\title{
The behavior of a co-flow structure to screen projects in a product pipeline
}

Paulo S. Figueiredo ${ }^{1}$ - Escola de Administração - Universidade Federal da Bahia

Elisabeth Loiola² - Escola de Administração - Universidade Federal da Bahia

ABSTRACT In many situations, System Dynamics modelers have to capture attributes of items tracked in an aging chain by means of a co-flow. This study presents an application of co-flows in aging chains: A co-flow that enables the process of screening, i.e. the process of either terminating or approving projects. The article is the fifth in a series of articles about the model. An application to Product Pipeline Management (PPM) is developed. A two-stage product development pipeline was modeled with a co-flow structure that tracks the number of projects and the related net present value of payoff. Managers at each stage must decide on capacity utilization and thresholds for minimum value of projects. Simulation results illustrate that screening can eliminate the backlog bullwhip effect in the pipeline.

Keywords Bullwhip. Decision Biases. Product Development. Screening. Stage/Gate. Product portfolio management.

1. Avenida Reitor Miguel Calmon, s/n, Vale do Canela, Salvador - BA, CEP: 40110-903, paulo_s figueiredo@hotmail.com 2. beloi@ufba.br

FIGUEIREDO, P. S.; LOIOLA, E. The behavior of a co-flow structure to screen projects in a product pipeline. GEPROS. Gestão da Produção, Operações e Sistemas, Bauru, Ano 11, no 4, out-dez/2016, p. 171-195.

D0I: 10.15675/gepros.v11i4.1559 


\section{INTRODUCTION}

New product development (NPD) projects are typically managed through a series of screens, or gates in a chain, where ideas compete for resources. Ideas are carved into projects, and these projects are reviewed, and approved or terminated through the screening process so that only the best performing projects continue to subsequent stages of design, development and testing, and are released into the market place (KRISHNAN; ULRICH 2001; TERWIESCH; ULRICH 2009).

This study presents a new application of co-flows in aging chains: A co-flow that enables the process of screening projects in a product development pipeline. Figure 1 shows a classic example of the use of a co-flow, adapted to the Product Pipeline Management (PPM) process, in which screening is present. This Figure is inspired on Clark and Wheelwright's (pp. $294,1993)$ classic representation of the pipeline, adapted to a system dynamics model and is adapted from Figueiredo and Loiola (2012, 2014a, 2014b) and Figueiredo et al. (2015). It demonstrates the simplest configuration of the process, i.e. the single-stage model with co-flow. This simplified representation shows how items (projects) are initiated, developed and moved to the review stock, in which they are evaluated and either completed and taken to the next stage, or terminated (COOPER et al., 1998). Most large companies genererate new products or patents regularly and have structured product development processes, such as was illustrated by Loiola and Mascarenhas (2013).

Wheelwright and Clark (1992) propose a typology for PPM projects, based on the degree of innovativeness and configuration of the project teams. The model presented here can be used to analyze firms that focus on all three kinds of projects (breakthrough, platform or derivatives), however it fits especially well to pharmaceutical innovation chains (FIGUEIREDO \& LOIOLA, 2012, 2014a, 2014b; FIGUEIREDO et al., 2015), where there is more homogeneity among projects.

While projects are being developed, value creation is being added to the co-flow. Such value (an attribute) accumulates in the "Value in Stage 1 Review" stock, and is either lost or transferred to the next stage together with the corresponding projects.

In order to know which part of the stock of items and of the stock of value has to be terminated, it is necessary to know the fraction of items that have a value lower than the predetermined threshold. In order to calculate such fractions, it is necessary to determine how the population of values of items is distributed, i.e. what the probability distribution function (PDF) of values is. The choice of different thresholds will result in a different fraction of projects that are accepted. A higher threshold will necessarily reduce such fraction. 
Figure 1 - Single stage Co-flow with screening (simplified).

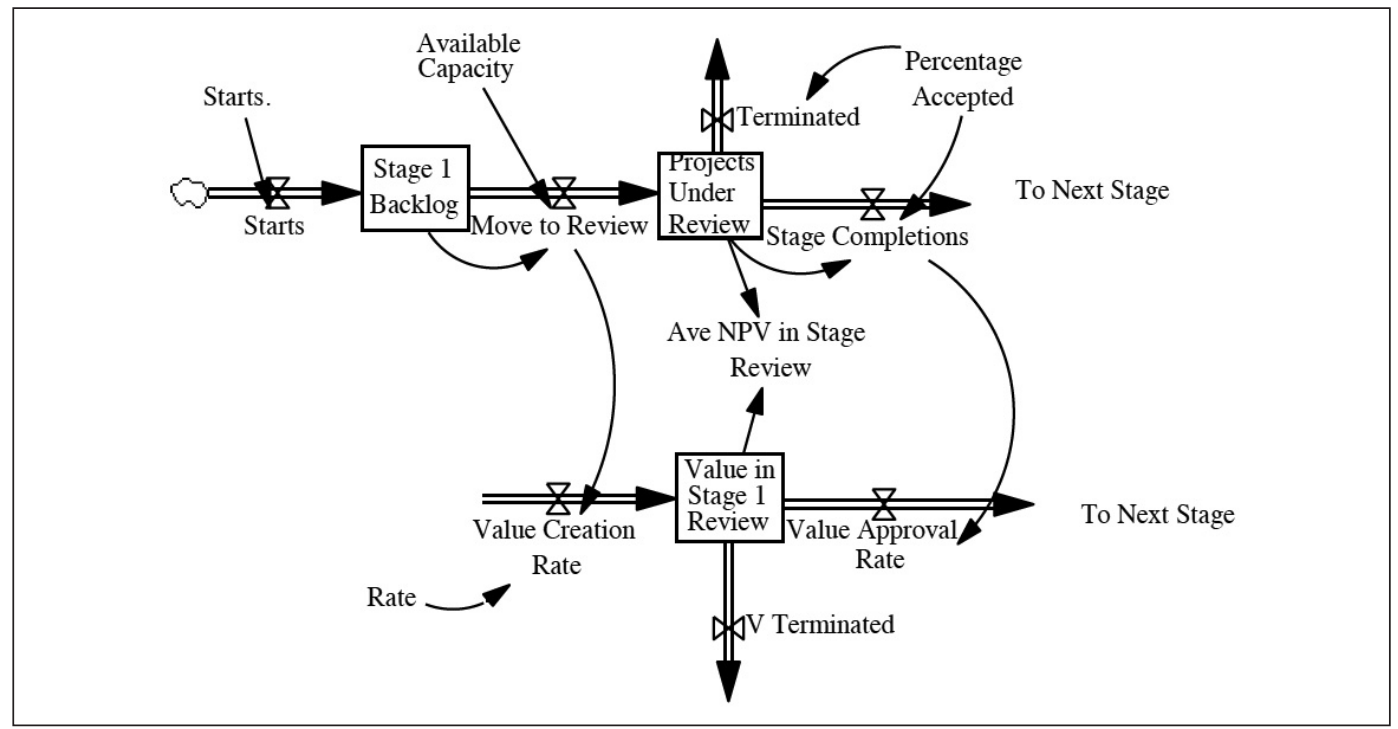

Source: Adapted from Figueiredo and Loiola, 2012.

This study builds upon research based on mathematical representations of the PPM chain. Most models available in the literature are of stochastic nature (COLVIN AND MARAVELIAS, 2011; BRIANNA; CREMASCHI, 2015; SUBRAMANIAN et al. 2003). But a few models, such as Anderson et al. (2005) and Varma et al. (2003), explore the dynamics of the process. The study by Varma et al. (2003) is based on discrete event simulation, however Anderson et al. (2005) developed a system dynamics model for service chains, from which Figueiredo and Loiola (2012, 2014a, 2014b) and Figueiredo et. al. (2015) derive. It is believed, based on the literature review that was undertaken, that these five latter models represent innovative work in the study of the bullwhip effect and the overall performance of ageing chains, more specifically the PPM innovation chain and service chains. The bullwhip effect is an observed phenomenon in chains or distribution channels. It refers to a trend of larger and larger swings (oscilation and amplification) in inventory or backlog, in response to changes in the upper part of the chain, as one looks at stages further back in the chain. The concept first appeared in Jay Forrester's Industrial Dynamics (FORRESTER, 1961) and thus it is also known as the Forrester effect. 
The present study steers away from analyzing conventional stage-gate processes that do not screen out items, and instead focuses on the funnels (ZAPATA; CANTÚ, 2008; JUGEND; SILVA, 2012). As was mentioned in Figueiredo \& Loiola (2012) and also in Figueiredo and Joglekar (2007), there are three key structures endogenous to the process of screening, namely 1) Capacity adjustment (how the throughput of projects will be adjusted), 2) Type of screening (minimum or maximum values can be selected) and 3) Relation between co-flow attribute (the risk-adjusted Net Present Value or NPV, a measure of financial performance) and throughput. This basic measure of performance is proposed by Cooper et al. (1998). The aforementioned authors stated that portfolio management shouldn't be undertaken using only financial parameters such as NPV. Other objectives while managing the chain, such as strategic issues and balancing issues are also important. However, NPV is a key performance measure (REYCK et al. 2004).

The third structure determines if changes in the co-flow attribute from one stage to the next will be affected by capacity utilization, i.e. by how intensively resources (people) are used, affecting the throughput of the pipeline in terms of flow of items. In NPD pipelines it is generally assumed that projects gain value as they are developed and taken to the next stage, and that the level of value gain depends on how intensively project teams are working (REYCK ET AL, 2004; WHEELWRIGHT; CLARK, 1992, pg. 91). The attributes tracked in a co-flow are also affected by the screening process itself, since some value is lost due to the termination of items. For instance, by selecting only the best performing projects, managers increase the average value of the surviving population of projects in a NPD pipeline. All the equations for the model can be found in Figueiredo and Joglekar (2007) and Figueiredo and Loiola (2012). The behavior of such model is studied, aiming to determine how the presence of screening changes the presence and intensity of the bullwhip effect in the chain.

The bullwhip effect is an observed phenomenon in chains, such as supply chains or NPD pipelines. It refers to a trend of larger and larger swings in the stocks of the chain, in response to changes in the rate of entrance of items, as one looks at stocks further back in the chain (FORRESTER, 1961).

In addition to greater safety stocks, the bullwhip effect can lead to either inefficient work activities or excessive inventory in the stocks, as each stage needs to fulfill the "demand" of its predecessor in the chain. In spite of having safety stocks there is still the hazard of stock-outs which result in financial losses. In addition to the (financially) hard measurable consequences of poor performance, an organization has to cope with the ramifications of failed fulfillment (of projects, or products etc.) which may include contractual penalties. Moreover, repeated hiring and dismissal of employees to manage the demand variability induces further costs due to training and possible lay-offs (BRAUNER et al., 2013). This is, therefore, an important problem to be tackled in a NPD chain. It is important to notice that while the bullwhip effect has been exhaustively explored in the supply chain literature, little has been done in the NPD literature. Studies that address this problem are therefore badly needed. 


\section{THEORY AND MODEL USE}

The model developed here represents product pipeline management (PPM) decision-making. The term product pipeline management alludes to the practice of starting and steering several NPD projects through a sequence of screens. The structure of stocks and flows in PPM can be compared to the structure of a service supply chain model (ANDERSON et al. 2005) as shown in Figure 2. Actually, the PPM dynamic model presented here builds upon and is fully compatible, derivative and a further development of the service chain model proposed by Anderson et al. (2005). This compatibility can be justified by the presence, in both chains, of processing flow-time and capacity constraints, which determine throughput in the chain. Anderson et al.(2005), showed that, depending on the relative magnitudes of processing time and capacity adjustment time, the service supply chain exhibits a backlog bullwhip, so that swings in stage 2 backlogs are larger than swings in stage 1 backlogs in response to perturbations in the customer demand.

This study is the fifth in a series of papers about the model. The contributions of these papers are summarized as follows:

a) $1^{\circ}$ paper - Enhancing New Product Development (NPD) Portfolio Performance by Shaping the Development Funnel. This paper shows the impact of structural and behavioral aspects of the key managerial decisions through a simulation based analysis of a pharmaceutical dataset.

b) $2^{\circ}$ paper - Screening items in an aging chain with a co-flow structure: an application to the product pipeline management problem. This paper presents many possible applications for the model, ie. a new application of co-flows in aging chains: A co-flow that enables the process of screening, namely the process of either terminating or approving items depending on an attribute.

c) $3^{\text {a }}$ paper - The Nature and Role of Complexity in Simulation Performance: The Case of Multi-Stage New Product Screening: The objective of this paper is to understand the nature and role of complexity in simulation performance. A system dynamics model of the product development pipeline was developed, and an online game based on that model was created. An experiment was run where subjects made a series of decisions on one or two variables for many periods, with different levels of information available to them (attribute complexity). The results confirmed the hypotheses relating degree of difficulty to distance from optimality. Two factors adversely affected the subjects' performance: dealing with more complex information on performance (more than one attribute) and having to make more than one simultaneous decision. The latter condition was more detrimental to performance than the former.

d) $4^{\circ}$ paper - The Effect of Longer Development Times on Product Pipeline Management Performance. This study shows that in the presence of loss of value due to longer lead times, it is more advantageous to: 
(1) Work faster to reduce the backlog of projects;

(2) Increase the number of projects started whenever it is possible reduce complexity in the pipeline; and

(3) The optimal decision on resource allocation is independent of the loss of value due to longer lead times.

Figure 2 - A Service supply chain (Anderson et al. 2005).

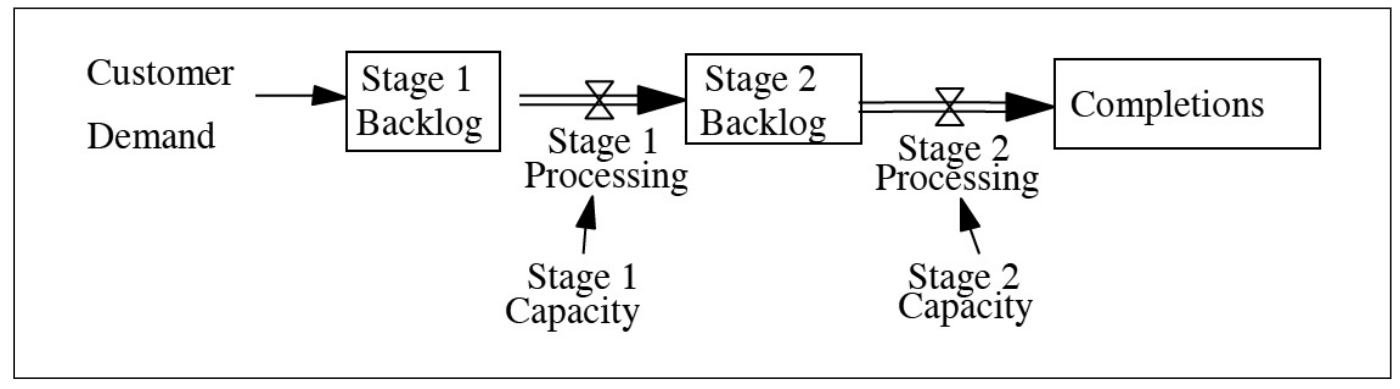

Source: Anderson et al. 2005.

The PPM problem is a special case of service supply chains where some projects are terminated across stages based, among other variables, on their value (REYCK et al. 2004, COOPER et al. 1998). However, it is not clear if the bullwhip effect will be evident in the presence of screens. Although this effect has been widely documented in ageing chains (ANDERSON et al. 2005; LEE et al. 1997), it is possible that the elimination of part of the items in the chain may reduce or even cancel out the amplification in oscillations that is characteristic of the bullwhip effect. In order to test for the presence of bullwhip effect, a slightly more complex chain is needed. Therefore, a two-stage model of the product development pipeline was developed for this study (Figure 3).

The behavior of the PPM problem is studied by formulating a System Dynamics model that tracks the number of projects and their value at each stage within a co-flow structure. The screening process is modeled by applying an extreme value probability distribution function (PDF) to the values of the population of values of projects that are at each gate or review point (DAHAN; MENDELSON, 2001; GUMBEL 1958; GALAMBOS 1978; FIGUEIREDO; LOIOLA 2014a). These projects are eliminated or approved depending on the percentage of projects below or above a pre-determined threshold.

Such a model allows the exploration of the following questions: (1) Is such a structure susceptible to backlog bullwhip? (2) What are the key drivers and determinants of the backlog bullwhip?

Simulation results show that the PPM model behavior can differ remarkably from conventional service supply chains. For instance, it is illustrated that the PPM process can indeed eliminate the backlog bullwhip. Implications of these findings and of the new system dynamics structures are discussed in the final section. 
Figure 3 - Tracking the Creation of Value in a Two-stage Product Development Pipeline.

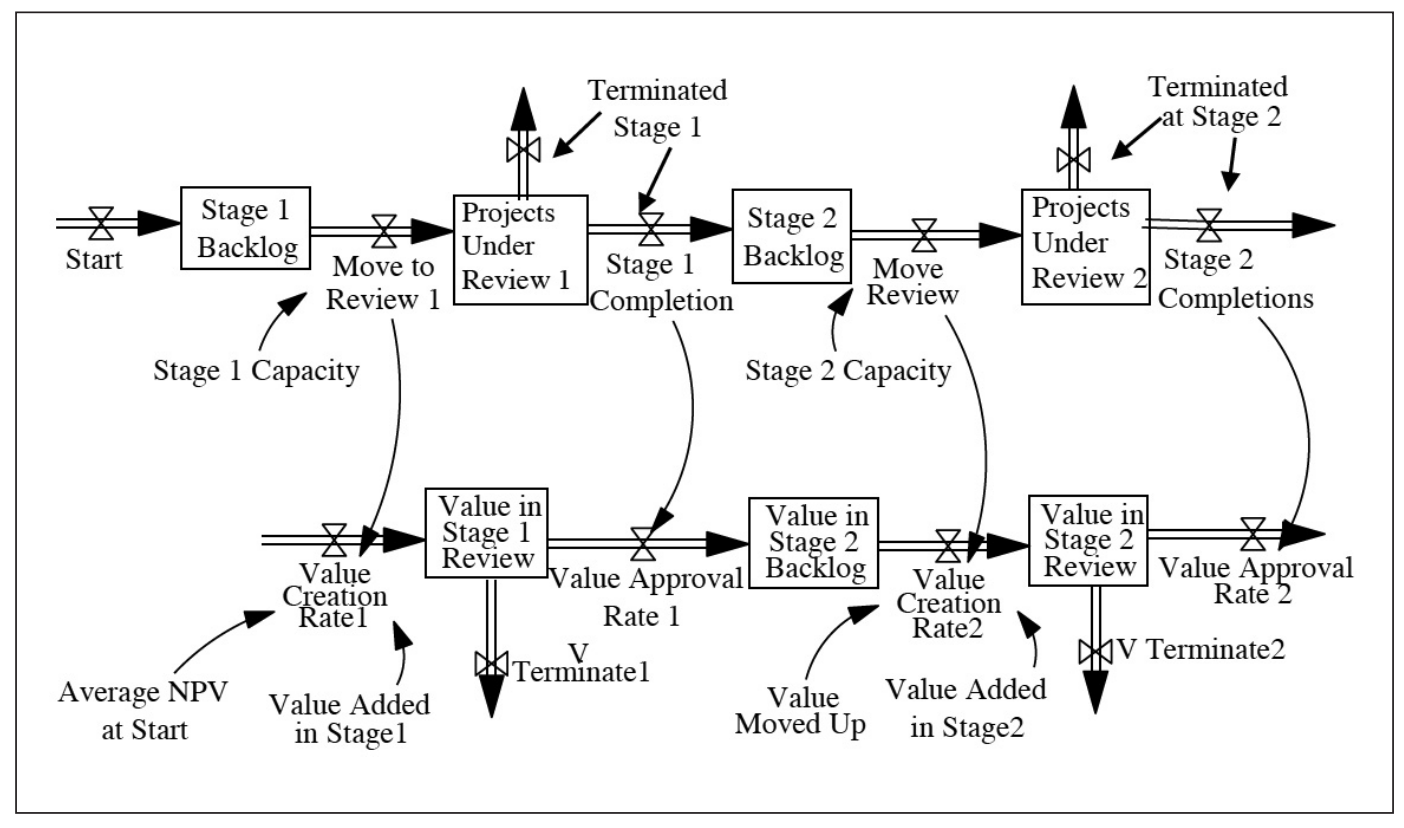

Source: Figueiredo and Loiola, 2012.

\subsection{Capacity utilization versus value creation trade-off}

NPD managers are often endowed with limited resources. However, their focus is not limited to efficient resource allocation under these situations. They are also interested in the trade-offs between value creation and throughput involving the product pipeline management decisions. A similar type of trade-off between quality and throughput has been studied in other settings such as the service industry. For instance, Oliva and Sterman (2001) identify "time per order," as a key construct that drives the service quality dynamics in a single stage model calibrated for a lending center at a UK bank. The applicability of service quality trade-offs has not been explored across an entire service supply chain and/or in service profit chains (HESKETT et al. 1997). However, capacity utilization has been identified as a key construct that drives the performance of service supply chains (ANDERSON et al. 2005).

In a product development pipeline, the available capacity of the development teams is adjusted frequently, in order to either adapt to the work demand of each stage of the chain with or to keep the utilization level around its nominal value (100\%), i.e. the value in which value creation is maximum (GIROTRA et al. 2005; WHEELWRIGHT; CLARK, 1992, pg. 91). This managerial decision is defined here as "capacity adjustment bias", which represents a tendency of managers to work faster to reduce backlogs or at the work intensity that improves capacity utilization. Therefore, value creation is assumed to occur in the pipeline, dependent on the level of capacity utilization (FIGUEIREDO; LOIOLA, 2012). 


\section{METHODOLOGY}

The methodology of the present study is simple. The product pipeline dynamic model is studied while configured to enable the presence of the bullwhip effect (ANDERSON et al., 2005). Simulations are run using base-case values for the variables (FIGUEIREDO; LOIOLA, 2012), and graphs are created to analyze under which conditions the bullwhip effect is mitigated. Special attention is given to the impact of screening activities in the chain, i.e. the termination of projects as they go from one stage to the next. A wide range of inputs are tested, and three-dimensional graphs are generated in order to show the relationships between the decision variables and the occurrence of the bullwhip effect.

The choice of parameters for the base case used in the model was not random (see appendix). Values were chosen so that the work intensity or capacity utilization would be kept at peak values (100\%), so that any changes in that value would result in a worst performance, either when the work intensity is increased or when it is decreased. The pipeline was calibrated for a steady state condition, in which value creation is maximal (FIGUEIREDO; LOIOLA, 2012).

This is a highly stylized model that comes with several simplifications. For instance, value creation rates and other variables were arbitrarily chosen; the model was not calibrated to a real company. This was a deliberate decision because a more generic version of the model can be useful for other applications. For a fully calibrated, three-stage version of the PPM model, check Figueiredo and Loiola (2012). Although the choice was arbitrary, criteria were defined for the ranges of the variables and limits of the simulation in order to develop a coherent model with the environmental reality in which the model was applied. The values of th variables did not result in ceiling effects, especially because the table functions defined for the screening process covered all values used in the simulations.

Dependencies among projects, such as sharing of resources and sub-additive pay-offs are also not accounted for (GIROTRA et al. 2005). Another simplification of this formulation is that the number of employees (in terms of man-hours per month at each stage) is fixed; therefore an increase in capacity is automatically translated into an increase in utilization. The average project complexity is also fixed (in terms of man-hours per project at each stage). In the model, fixed resources are evenly distributed among stages (nominal_capacity_1 = nominal_capacity_2 $=5$ ), however in many situations, resources may be allocated globally according to the necessity of each stage. Total capacity could then be shared by both stages unevenly. Average project complexity could also be a defined as a decision variable. These constitute very simple but important improvements to the model and can be found in Figueiredo and Loiola (2012). 


\subsection{Object of study: model description}

Most firms use multiple, typically four to six, gates in their pipelines (GRIFFIN, 1997; ULRICH; EPPINGER, 2004). For parsimony, the model incorporates only two gates as shown in Figure 3. This simplification was a necessary measure and does not compromise the analysis, since a longer chain is basically a repetition of the same basic structure found on a two-stage chain. All the variables found in one stage can be found in the next, and the same process of screening is performed (FIGUEIREDO; LOIOLA, 2012). Outcome variables of interest are total value created and average value created at the end of the pipeline. The independent variables in the model are number of projects introduced into the pipeline, minimum acceptable value in each stage (thresholds 1 and 2), and managerial biases while adjusting capacity. As explained in the introduction, the model structure can be divided in three basic processes. Such key processes determine the flows in the pipeline, the performance measures and the selection of items. These are described in the first paper of the series (Figueiredo and Loiola, 2012).

The system dynamic structures detailed in the previous paper contain the key decision levers which are the focus of this study: variable Alfa, i.e. the managerial bias while adjusting capacity, and the time ratio, i.e. the ratio of nominal (minimum) development time and time to adjust capacity. The latter variable determines if there will be backlog bullwhip in the main flow of traditional aging chains, as shown by Anderson et al. (2005). Variable Alfa was defined as a tendency to either work more intensively to reduce backlogs or work at the intensity that maximizes value creation. Alfa is normalized as a value between zero and one. A value of one means that managers adjust capacity utilization as needed to reduce backlogs. A value of zero means that managers aim to keep the capacity utilization of workers at a point where value creation is maximum. Any intermediary value of Alfa can be chosen, as long as it is between zero and one. Since this variable affects how capacity changes over time in the chain, it has a crucial effect on the oscillation and amplification in the size of backlogs.

\section{RESULTS}

This section presents the results and discussion of the analyses performed with the model.

\subsection{Model behavior}

A series of tests was conducted to build confidence in the model structure and behavior (FORRESTER; SENGE, 1980), and to determine in which conditions the model is susceptible to the bullwhip effect, if any. 


\subsubsection{Behavior of a single-stage model}

Initially, it is studied how the stock and flow of a one-stage model behave under different work intensity biases. It is clear that if managers have a bias towards reducing backlogs, then the size of backlogs should be reduced and the corresponding flow of projects should be increased, at least temporarily.

The capacity adjustment bias affects backlogs, flows and value creation only when the pipeline has an overflow of projects and there are potentially high utilization rate(s), above $100 \%$. When there is starvation of projects, the target capacity will be always the same (the maximum possible), regardless of the direction of the bias. In other words, when the maximum capacity is below $100 \%$, it doesn't matter if managers have a bias towards achieving nominal capacity or towards reducing the backlogs faster. The target capacities in both cases will be the same. Therefore, in order to test the effect of the work intensity bias on the backlog of projects and on capacity, a high number of starts (10 projects per month) were chosen. The other parameters were kept the same as the "base case". See table 1 in the appendix for details.

Results, as seen on Figures 4 and 5, confirmed the expectations. The size of backlogs was significantly reduced in the presence of a managerial bias towards reducing backlogs $(\alpha=1)$. The flows were evidently reduced when there was a bias towards improving capacity utilization, however mostly temporarily, since the stocks reached "steady-state" equilibrium conditions that were close together. Only when the bias towards improving capacity utilization was at extreme levels (such as 0 ), the flow of projects was permanently reduced.

Figure 4 - Effect of work intensity bias on Backlog.

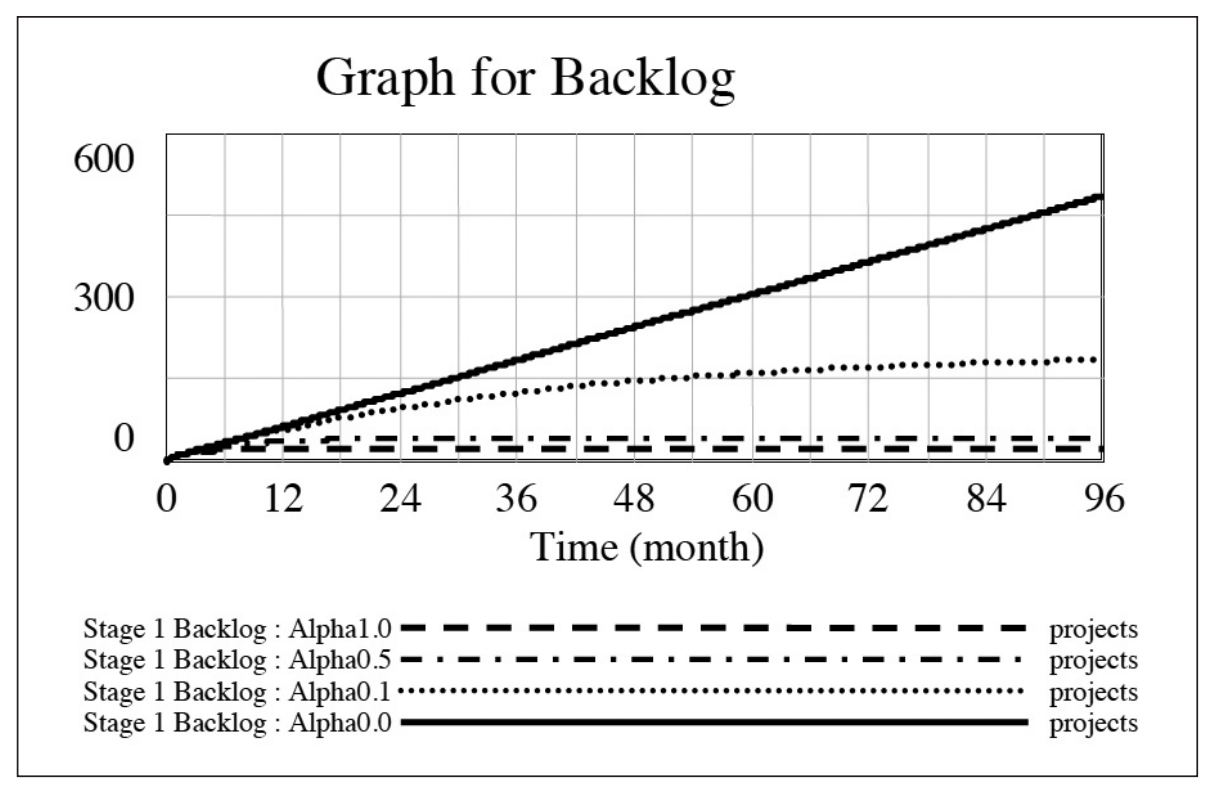

Source: Preparation of authors. 
Figure 5 - Effect of work intensity bias on outflow.

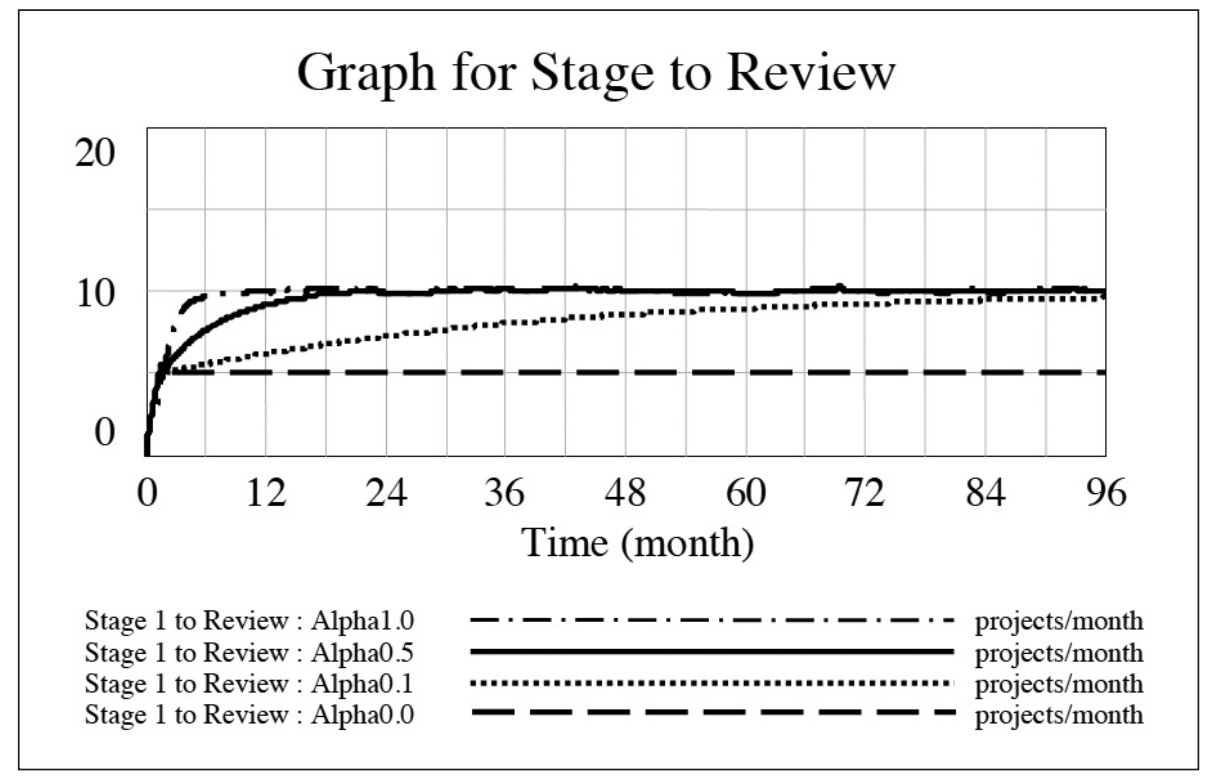

Source: Preparation of authors.

Next, the effect of high number of starts is described, with respect to the nominal development capacity, on the backlogs. The number of starts is set at a relatively high value of 7.5 projects per month, and a policy bias towards improving capacity utilization $(\alpha 1=\alpha 2=0.05)$. In such condition, pipeline capacity blocks some of the projects. This situation is termed an untouched backlog at the front end; backlog size increases monotonically over time. The graph is not shown here for brevity.

\subsubsection{Behavior of a two-stage model}

In order to determine the effect of screening on the flow of projects and on backlog bullwhip (ANDERSON et al., 2005) in a two-stage pipeline, the number of starts is initially set as a step function that initiates with zero projects and introduces 5 projects at step time 12 , and choose the "base case" settings for the other parameters (see appendix for details) in order to analyze the behavior of selected variables: the rate of projects that go into and through the pipeline and backlogs at each stage. Figure 6 illustrates the outcome of this simulation: the number of starts per period and the number of projects completed per period, at stages 1 and 2. Stage 2 completion rate is slightly below stage 1 completion rate, as expected, because some of the projects are terminated during stage 1 . 
Figure 6 - Starts and Completion Rates versus Elapsed Time.

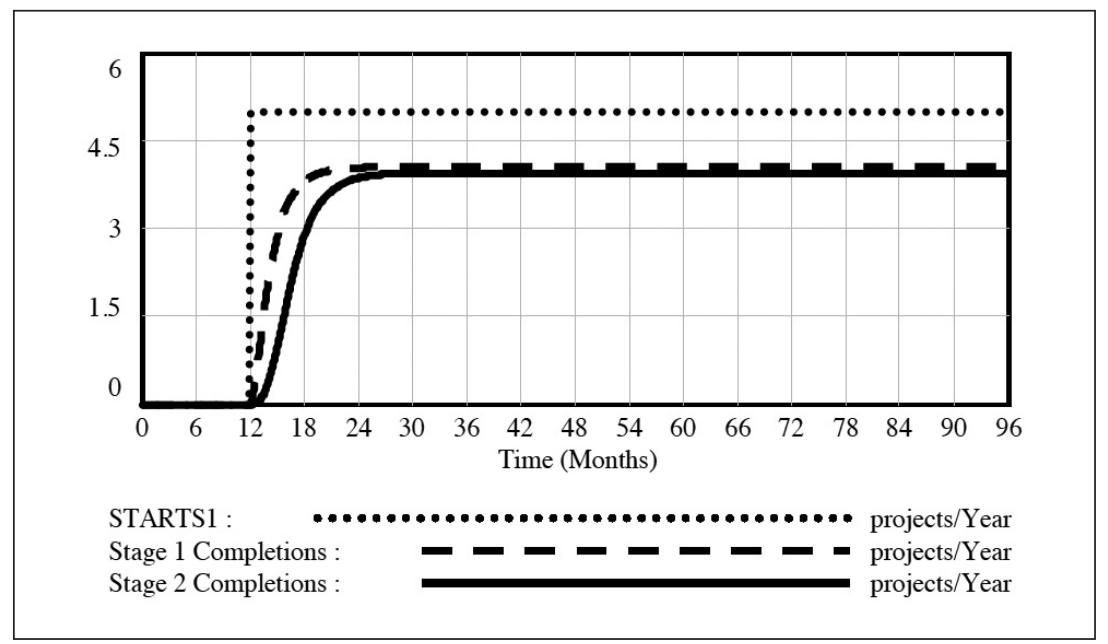

Source: Preparation of authors.

In order to test for the presence of a bullwhip effect, parameters are set to extreme conditions: both thresholds are set to low settings (threshold1=threshold2=-5) so that virtually all projects are approved. The managerial bias is set towards extreme values for reducing the backlog $(\alpha 1=\alpha 2=0.99)$ and a constant number of starts is introduced (5 projects per month) beginning in the twelfth month. The conditions that enable a backlog bullwhip effect are also introduced (ANDERSON et al., 2005) by setting up the time to adjust capacity at 8 months and the nominal development time at 2 months. The result is presented on the left hand side of Figure 7. Indeed, a backlog bullwhip effect is observed. The right hand side of Figure 7 shows the model's behavior with the same parameters, but with screens in place (threshold $1=1.68$ and threshold2=3.09). Screening eliminates the backlog bullwhip.

Figure 7 - Screening can eliminate Backlog Bullwhip on the pipeline.
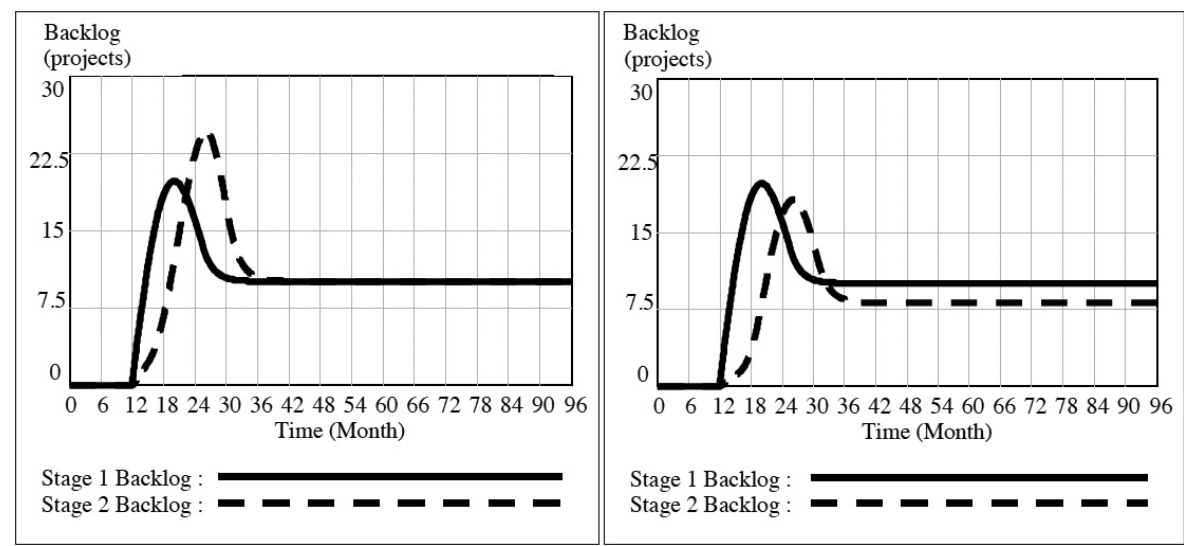

Source: Preparation of authors. 
In order to determine more precisely how the bullwhip effect depends on choices of capacity adjustment bias and on the relation between nominal development time and time to adjust capacity ("time ratio"), thresholds are set either to -5 (no termination condition) or to medium values, and a high value of starts is introduced ( 7.5 projects/month) at month 12 , together with a medium value creation rate (1.68, i.e. $68 \%$ of gain). Simulations are stopped at month 96 as before, and cover a wide range of possible values for $a$ and time ratio. Values found at time $\mathrm{t}=96$ are used.

Figure 8 shows the peak value of backlog 2 divided by the peak value of backlog 1, here called "bullwhip index" for every combination of capacity adjustment bias (Alfa) and time ratio, in a condition without screening. Figure 9 shows the same amplification or bullwhip index in the presence of screening. These graphs show how the bullwhip effect depends on the configurations of the pipeline. A higher value of the bullwhip index (more than 100\%) indicates the presence of the bullwhip effect. The corresponding graphs for average value at each stage are essentially flat curves, not shown here for brevity, but they show how screening and development increase the value amplification index (peak value 2 divided by peak value 1) from around 1.6 to 2 .

Figure 8 - Peak Backlog amplification index w/o Screening. Constant Value Creation rate.

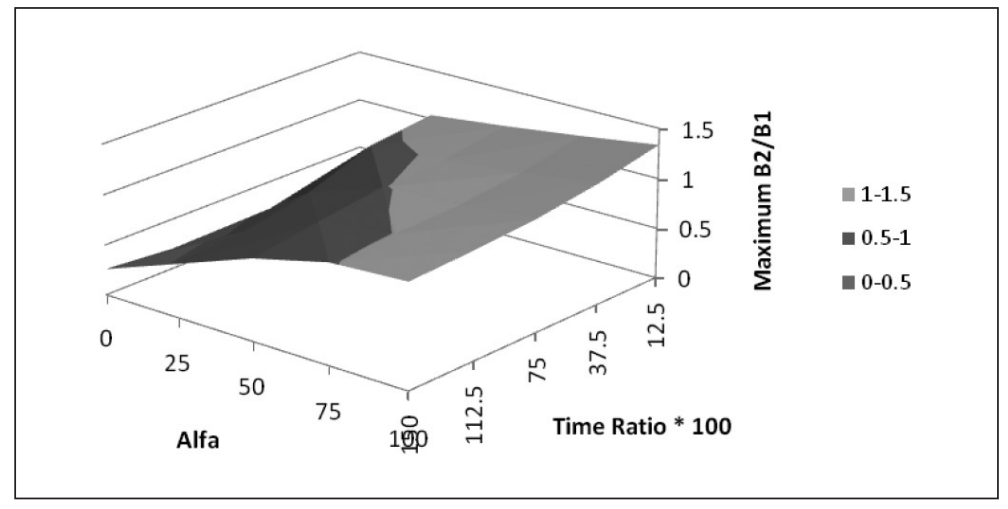

Source: Preparation of authors. 
Figure 9 - Peak Backlog amplification index w/Screening. Constant Value Creation rate.

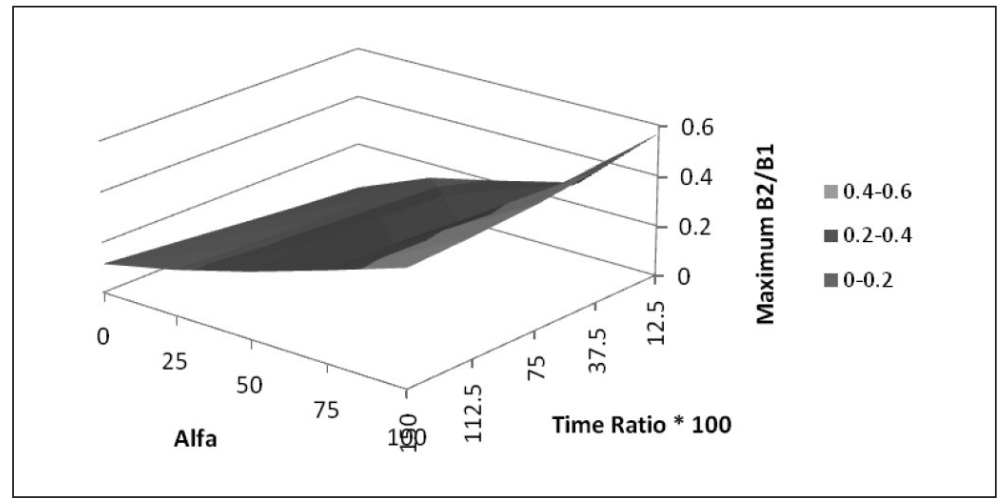

Source: Preparation of authors.

It is clear that the backlog bullwhip effect is enabled only when time ratio is reduced, as predicted by Anderson et al.(2005), together with a high value for alfa, i.e. in the presence of a bias towards reducing backlogs. Also, Figure 9 shows how screening can eliminate the bullwhip effect, since an amplification index larger than 1 is never reached. Moreover, screening and development increase the value amplification index. There is no convexity when value creation rate is constant. These Figures were not shown here, for brevity.

\subsection{Variable value creation and robustness of results (extreme conditions test)}

While the behavior of the model was consistent with expectations, the simplifying assumption of constant value creation rates may have an effect on termination rates, and therefore affect the flow of projects to the second stage, and value creation.

A relevant assumption for this study is that the relationship between capacity utilization and value created in each gate, instead of being constant, has an inverted $U$ shape, with the peak value being observed at nominal value of utilization. The nominal value of capacity utilization is set to be at unity (as shown in the appendix.). This assumption follows field observations by Wheelwright and Clark (1992) and by Girotra at al. (2005). The former authors show how employee productivity (percent of time spent on value-adding tasks) initially increases and then decreases as the number of development projects assigned concurrently to each engineer increases. The latter authors have pointed out that total development costs can be thought of as the sum of opportunity costs and the cost of capacity, resulting in a convex function of capacity utilization. In sum, there is an interior utilization level (a position between the two extremes of the curve) that maximizes firm profit. Utilization affects the dynamics across multiple stages in a product development pipeline: after introducing a very large number of 
projects, utilization goes up above its nominal value and reduces the relative amount of value added for each project. Utilization goes down when a stage is starved of projects, and that too reduces the relative amount of value added to each project. The average value of projects is normalized to unity at start. This value is subsequently multiplied by a factor ranging from 1.35 to 2, depending on the utilization, as the projects that were in the backlog are developed and go to the next phase to be reviewed. A step function to starts is introduced, with a value of 7.5 projects at time $t=12$. Then the endogenous value creation case is compared with the constant value creation case (with a fixed value gain of $100 \%$, an extreme condition).

It is clear that once value creation is allowed to decrease due to lower (or higher) capacity utilizations, the rate of completions on the first stage is reduced, the backlogs on the second stage are also reduced in size, and less value is transferred to the second stage (Figures 10, 11, and 12 respectively below). In such configuration, less value is created and more projects are terminated, causing reduction in performance. The physical meaning of this finding is simple and intuitive. If there is a trade-off between performance and work capacity (too much of too little work intensity harms performance), then some value is lost due to a non-optimal work intensity of the development teams, and more projects are terminated due to the inferior quality. On the other hand, if workers always operated at the ideal work intensity, i.e. the peak value, then the discrepancies between the curves in Figures 10, 11 and 12 would not exist.

Figure 10 shows how considerably fewer projects are completed once such a phenomenon is taken into consideration. Figure 11 shows how the endogenous value creation rate reduces the size of the backlog of projects, since fewer projects are being evaluated due to a higher termination rate. Figure 12 shows how the rate of value being taken from the first stage to the second stage is reduced when value creation is allowed to change depending on capacity utilization.

Figure 10 - Effect of concave value creation curve on exit flows of 1st stage.

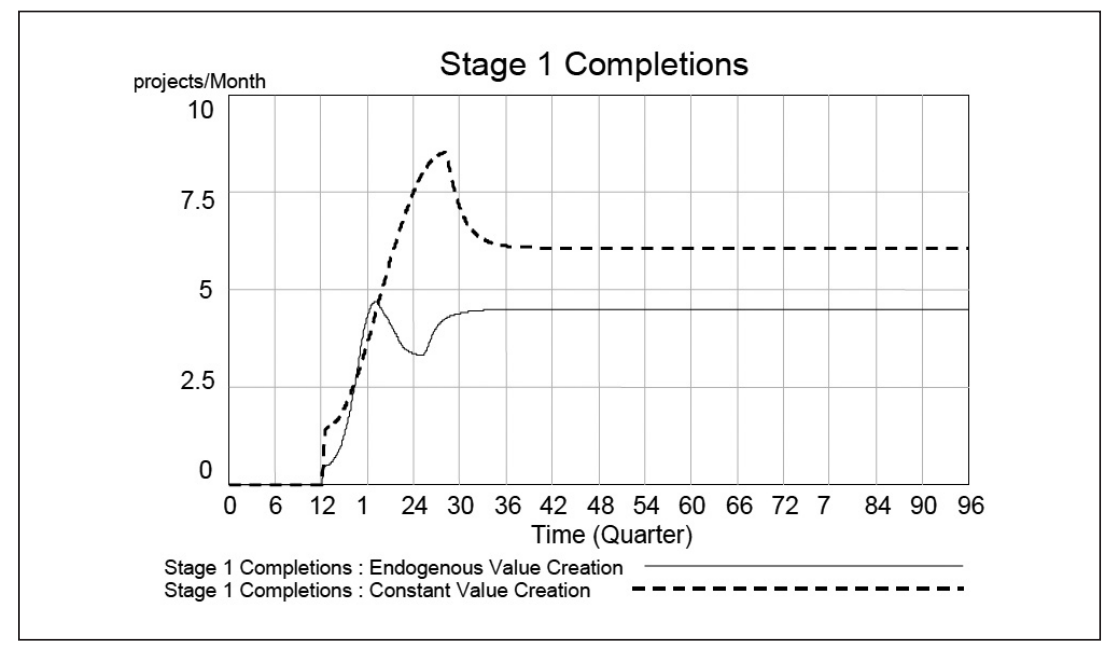

Source: Preparation of authors. 
Figure 11 - Effect of concave value creation curve on backlog of 2nd stage.

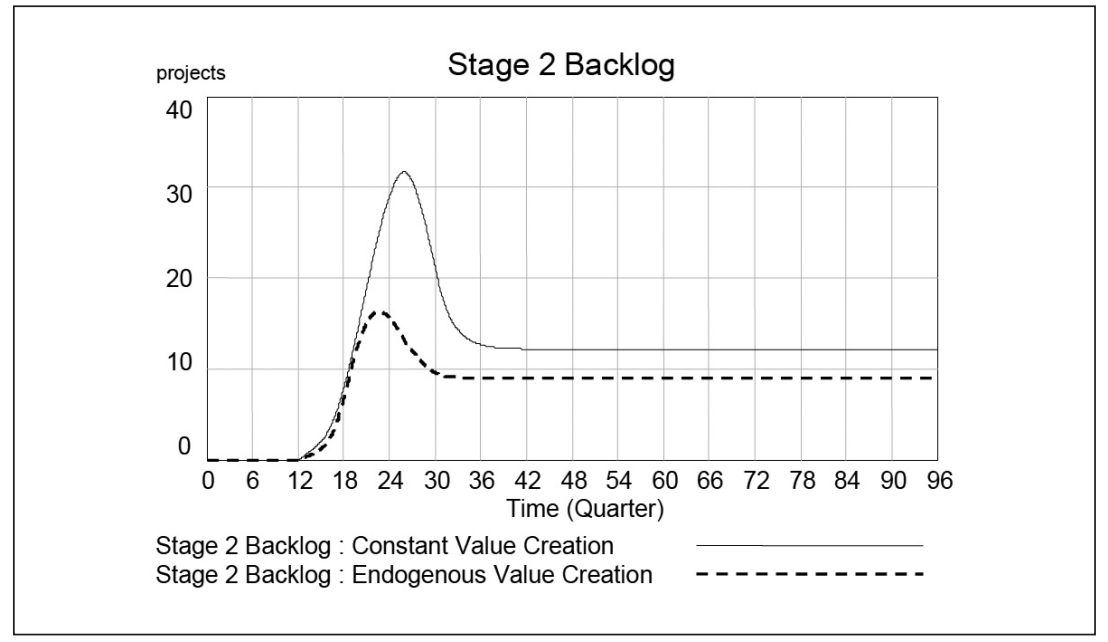

Source: Preparation of authors.

Figure 12 - Effect of concave value creation curve on value approval rate of 1st stage.

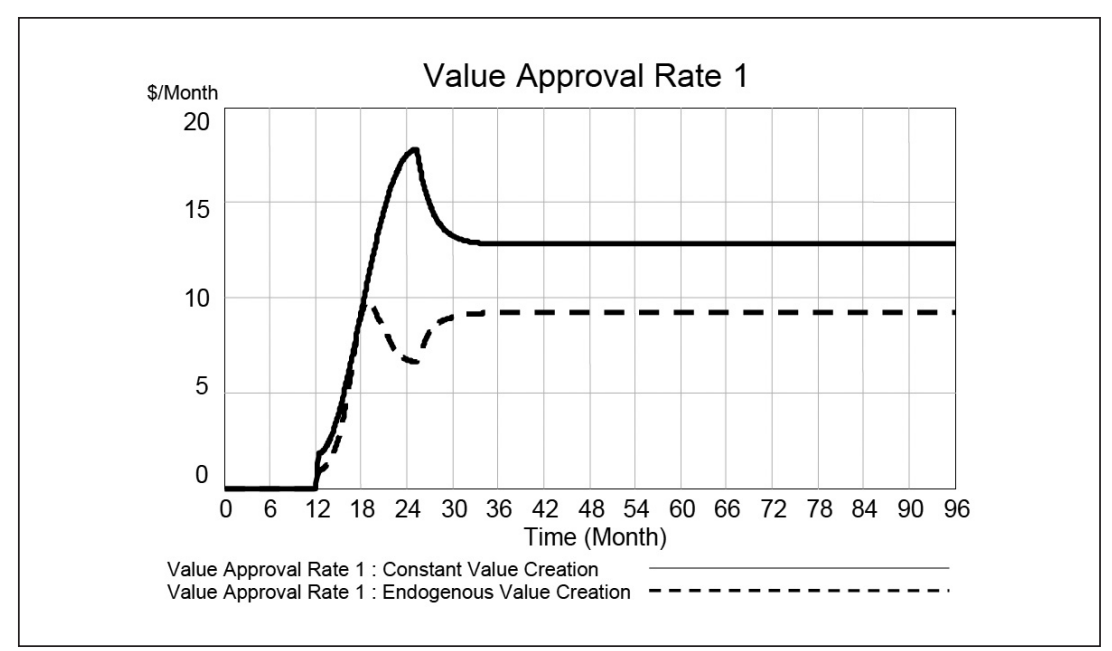

Source: Preparation of authors. 
While the simplifying assumption that value creation is constant at $100 \%$ is in itself an extreme conditions test, since value creation is maximum, additional tests were run to build confidence in the model. By eliminating the screening process, while keeping other parameters at "base case" values, high utilization rates are reached at the second stage, increasing the number of projects to be reviewed (see Figure 13). This test was performed to check if there are ceiling effects in the model under the configuration used in the study, i.e. it was tested whether any variables hit maximum values, affecting the validity of the model's assumptions. The test was successful and no ceiling effects were detected.

Figure 13 - Rate of projects to be reviewed on 2nd stage, with and without screening.

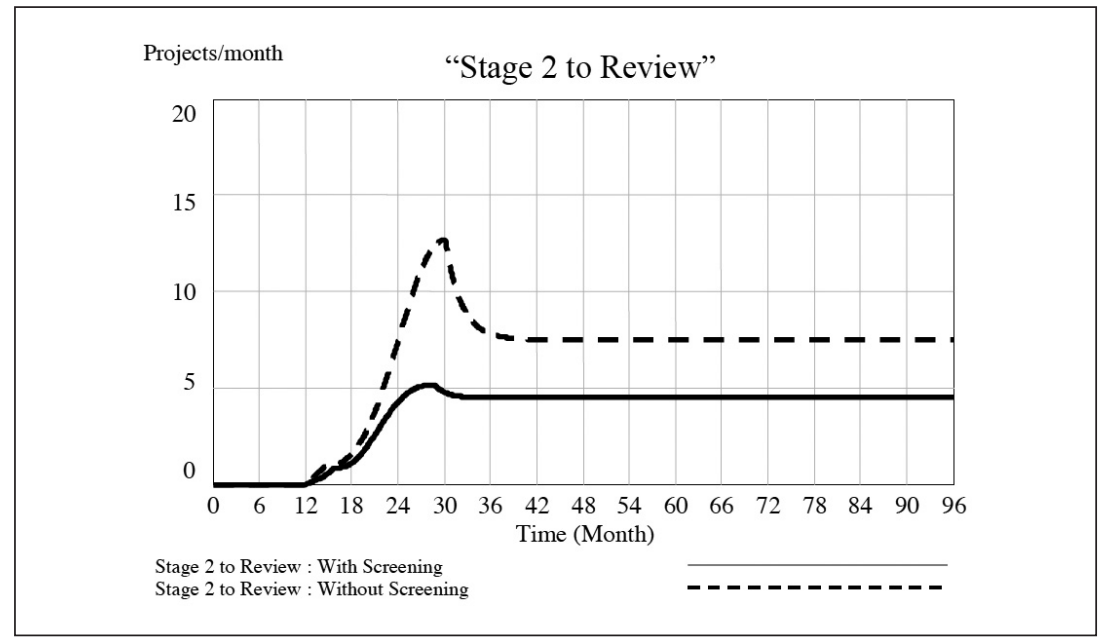

Source: Preparation of authors.

It is possible to conclude that the model behaves extremely well as long as parameters are kept under reasonable values. Only when very high utilization or value creation rates occur, ceiling effects can take place due to the limited ranges of the table functions for thresholds (screening) and the utilization versus value creation table. These effects can be remedied by extending the tails of the table functions accordingly. In the study, ceiling effects were minimized by choosing values for variables in such a way that the limits of the aforementioned functions were not reached.

The next couple of Figures show the backlog index (peak of backlog 2 divided by peak of backlog 1) for the "endogenous value creation" condition. The results are very similar to the ones of the "constant value creation" condition; Backlog Bullwhip is created with specific conditions, i.e. high Alfa and low time ratio. Furthermore, backlog Bullwhip can be completely eliminated when screens are in place. But there is a key difference, since there is convexity of peak value amplification index (peak value 2 divided by peak value 1 ) in relation to the capacity adjustment bias (Alfa), for both screening conditions. These two Figures are not shown for brevity purposes. This relation can be explained by the trade-off between value creation vs. capacity utilization. 
More importantly, results for both value creation conditions show that the peak for backlog stock and its covariant (value) peaks are out of sync in terms of "Alfa" and "Time Ratio", owing to the physics of the flows. Ergo, policies that minimize "backlog bullwhip" may not be the best policies to minimize "value bullwhip".

Figure 14 - Maximum Backlog Amplification index without Screening.

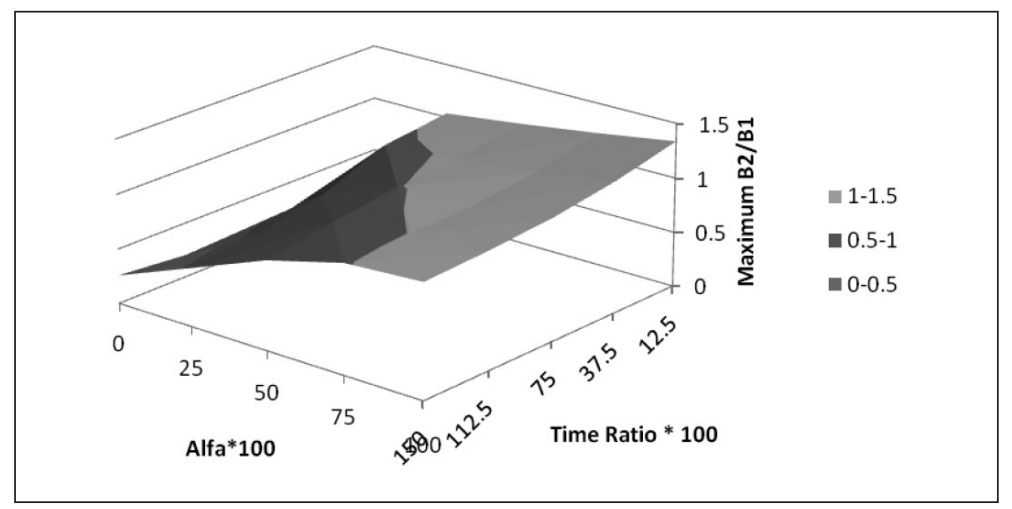

Source: Preparation of authors.

Figure 15 - Maximum Backlog Amplification index with Screening.

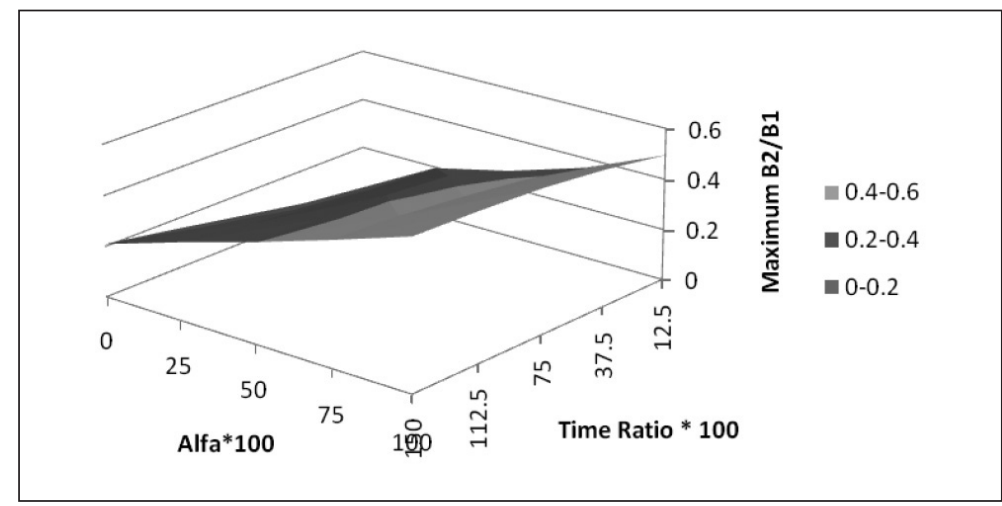

Source: Preparation of authors. 


\subsection{Random value creation}

In order to check the robustness of results with constant value creation, random uniformly distributed noise is added to the value creation process. Results are presented on Figures 16 and 17. These show that backlog amplification is similar to the previous case. Therefore peak backlog depends mostly on capacity adjustment and screening, not on NPV creation. Results for value amplification are also similar to the constant value creation rate case. There is no convexity in relation to value amplification index (which is around 1.75 without screening and 2.2 with screening). These results were not show for brevity. It is important to point out that the response surface also depends on the parameters of the filter (especially on the standard deviation, which was assumed to be constant); such analysis is not shown here.

Figure 16 - Maximum Backlog amplification index w/o Screening. Random Value Creation rate.

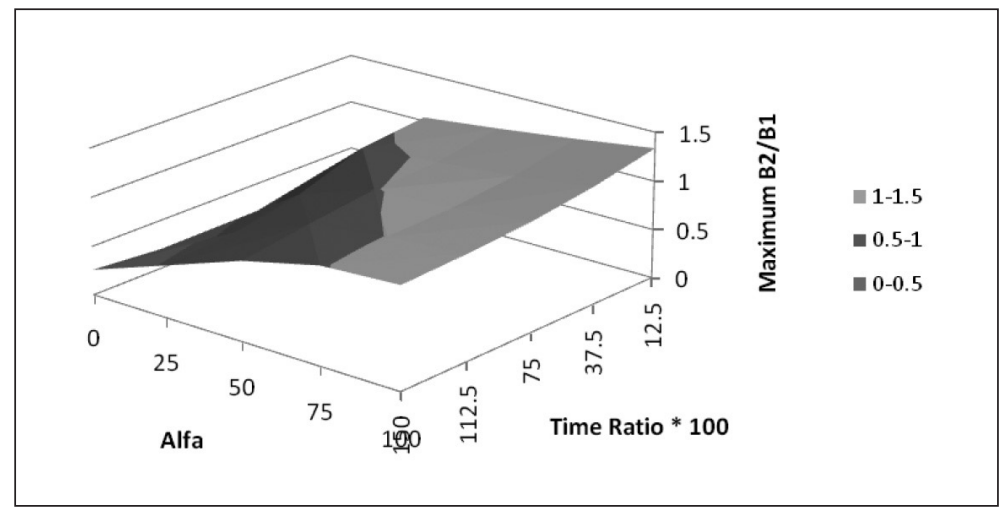

Source: Preparation of authors.

Figure 17 - Maximum Backlog amplification index w/ screening. Random Value Creation rate.

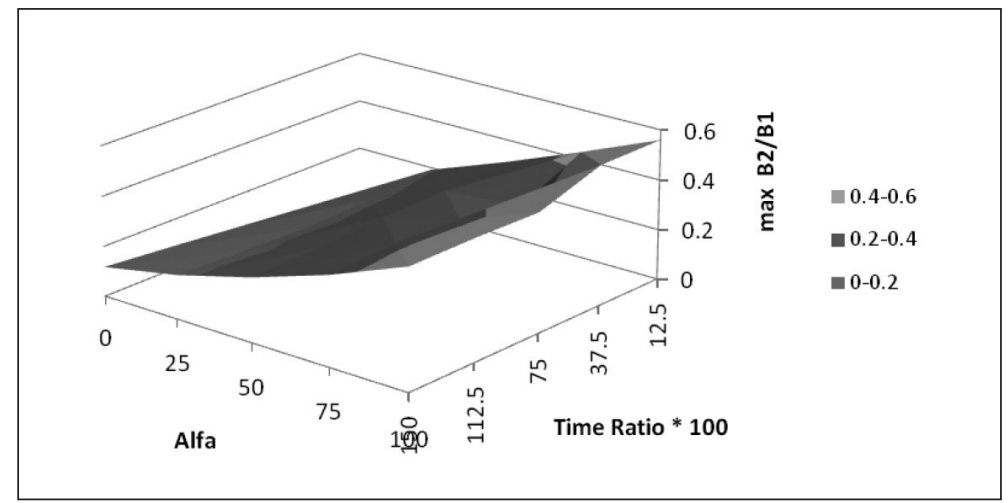

Source: Preparation of authors. 


\section{DISCUSSION}

The limitation of managers' ability to account for the supply line and backlogs has been documented extensively in the inventory/services management context (STERMAN 1989, ANDERSON et al. 2005). A related avenue for research, within the product innovation context, is to generate policy guidelines about the dynamics of capacity, resource utilization and backlog management while accounting for behavioral biases related to product innovation (SCHMIDT; CALANTONE 2002, SCHMIDT et al. 2009, GINO; PISANO 2005). Developing formal models on the economics of screening, in the presence of complexity and resource tradeoffs, either at a single stage or in a cascade of stages, and accounting for behavior bias (GINO ; PISANO, 2005) offers opportunities for follow on work. This study is a first effort in the analysis of the bullwhip effect in chains where the process of screening is present. No other study with such focus was found in the literature.

This study focuses on product pipeline management (PPM), but it could serve as a template for many others. Other businesses and social processes, in which screening is present, represent huge investments by firms and the value of human lives. A deeper understanding of such processes, from simulation-based insights, could help improve public and private policies. The detailed criteria adopted in process of screening for the model can be found in Figueiredo and Loiola (2012).

The typical behavior of the model was analyzed by focusing on how it reacts to a sudden change in one of its inputs (the number of projects started). Amplification and oscillation can be present in both the stocks of the main flow and the co-flow, under certain conditions. Even though this oscillation and amplification is a positive sign for the presence of bullwhip in the main flow of projects, it cannot be taken as bullwhip for the co-flow of net present value, since there is additional amplification caused by the creation of value during development and the selection of the best projects. Further research is necessary in order to create a specific bullwhip construct for the co-flow variable.

A key finding of the analysis presented here is that results for both value creation conditions show that the peak for backlog stock and its covariant (value) peaks are out of sync in terms of "Alfa" and "Time Ratio", owing to the physics of the flows. Therefore, policies that minimize "backlog bullwhip" may not be the best policies to minimize "attribute bullwhip". This adds much complexity to the product pipeline management problem. It can be argued that an "attribute bullwhip" is ultimately more important than a "backlog bullwhip", since the performance variable in the model is the attribute. However, if our simplified model took into account other financial impacts of the bullwhip effect, such as cost of starvation of projects, cost of delays and damages to the image of the company, the analysis would be more precise and complete. Based on the analysis presented here, however, it can be argued that policies to mitigate "attribute bullwhip" should be prioritized over policies to mitigate "backlog bullwhip". Our results show how this can be accomplished by: (1) Choosing to work as constantly as possible at the capacity utilization rate that maximizes value creation (i.e. the 
teams should work at nominal levels, producing work at the rate that maximizes its quality and value) and (2) Adjusting the variable "Time Ratio", i.e. the ratio of nominal (minimum) development time and time to adjust capacity. it can be argued, however, that the company has little control over the "Time Ratio" variable.The results presented here are meant to be descriptive in their nature. Even though policies can be created to mitigate the bullwhip effect on the chain, it is reasonable to assume that the key performance variable is total output, i.e. total value created during a certain period (FIGUEIREDO; LOIOLA, 2012). However, the negative consequences of the bullwhip effect are well documented: excess inventory or backlog of items, oscillation and amplification of variation, inefficient operation, stock-outs or starvation in the chain, poor service or lost service, damage to the image of the company due to delayed release dates, costs with overtime, etc.

Since the objective of the model is to describe a basic common structure to the screening process, its decision or independent variables were not endogenized. The development of a model based on longitudinal data and additional behavioral information would allow some of these variables to be endogenous. For example, it is reasonable to assume that in product pipeline management, managers take into account capacity utilization when deciding on the number of projects to be started. Such additions to the model could be explored on follow-on studies

\section{CONCLUSION}

This study presents the simulation results from a new structure to system dynamics models as defined in the previous papers about the model (FIGUEIREDO; LOIOLA, 2012, 2014a, 2014b; FIGUEIREDO et al.., 2015). Such structure accounts for a specific phenomenon, the screening of items from the stocks in the chain. It is hoped that the model presented here will serve as a basis for studies many areas, generating insights for practitioners and scholars. The goal is to explore the sensitivity of the more informed developer about the decision variables related to product pipeline management, so that managers will have more control over the process.

The manner in which the model has been set up differs from inventory/ service supply chain models (STERMAN 1989, ANDERSON et al., 2005) both in terms of stock/flow and policy structures. The key structural difference is that inventory and service supply chain models do not usually have exit flows (aka screens).

For the parameter set used in the tests, the PPM model does not exhibit any bullwhip when the screens are in place. However, under extreme conditions (FORRESTER; SENGE 1980), when the screens are eliminated (thresholds $=0$ ), together with a bias towards reducing backlog and a specific choice of nominal development times and time to adjust capacity, the model reverts back to a bullwhip effect similar to that found in a service supply chain. These results can be used to generate policies to mitigate the bullwhip effect in NPD chains: 
a) First, it was possible to confirm that the specific conditions that enable the presence of the bullwhip effect in service chains are valid for the PPM configuration;

b) Second, the process of screening contributes to reduce the bullwhip effect, partially avoiding its harmful consequences. This is an intuitive conclusion but had not been previously tested in the literature.

These are intuitive conclusions but had not been previously tested in the literature. They show that, specifically for the NPD chains or other chains where screening of items is present, the bullwhip effect may be a less important issue to managers, dependent on the intensity of the screening process that takes place. For the theory, it confirms the conclusions of Anderson et al. (2005) regarding the factors enabling and determining the presence of the bullwhip effect, however in a more complex setting.

In conclusion, PPM is a well established business process within the NPD community. However, extant literature aimed at managerial insights in this realm has been based on descriptive and empirical analyses. The PPM model is offered as a complementary tool for providing simulation based insights into the dynamics of project screening in a product development pipeline.

\section{REFERENCES}

ADLER, P. S.; MANDELBAUM, A.; NGUYEN, V.; SCHWERER, E. From project to process management - An empirically-based framework for analyzing product development time. Management Science, v. 41, n. 3, p. 458-484. 2005.

ANDERSON, E. G.; MORRICE, D. J.; LUNDEEN, G. The "physics" of capacity and backlog management in service and custom manufacturing supply chains. System Dynamics Review, v. 21, n. 3, p. 217-247. 2005.

BANERJEE, S.; HOPP, W. J. The Project Portfolio Management Problem. Department of Industrial Engineering and Management Sciences, Northwestern University, 2001.

BAUMEISTER, R. F.; TICE, D. M.; HEATHERTON, T. F. When Ego Threats Lead to Self-Regulation Failure: Negative Consequences of High Self-Esteem. Journal of Personality \& Social Psychology, v. 64, n. 1, p. 141-156. 1993.

BRAUNER P.; RUNGE S.; GROTEN M.; SCHUH M.; ZIEFLE M. Human Factors in Supply Chain Management. Lecture Notes in Computer Science, v. 8018, p. 423-432. 2013.

BRIANNA, C.; CREMASCHI, S. Heuristic solution approaches to the pharmaceutical R\&D pipeline management problem. Computers and Chemical Engineering, v. 74, p. 34-47, 2015.

CLARK, K. B.; WHEELWRIGHT, S. C. Managing New Product and Process Development. Free Press, NY. 1993. 
COLVIN, M.; MARAVELIAS, C. T. R\&D pipeline management: Task interdependencies and risk management. European Journal of Operational Research, v. 215, n. 3, p. 616-628, 2011.

COOPER, R. G.; EDGETT S. J.; KLEINSCHMIDT E. J. Portfolio Management for New Products. Perseus Publishing, MA. 1998.

DAHAN, E.; MENDELSON, H. An extreme-value model of concept testing. Management Science, v. 47, n. 1, p. 102-116. 2001.

FIGUEIREDO, P. S.; LOIOLA, E. Enhancing New Product Development (NPD) Portfolio Performance by Shaping the Development Funnel. Journal of TechnologyManagement \& Innovation, v. 7, n. 4, 2012.

FIGUEIREDO, P. S. LOIOLA, E. Screening Items In An Aging Chain With A Co-Flow Structure: An Application To The Product Pipeline Management Problem. RAI - Revista de Administração e Inovação, v. 11, n. 1, p. 97-114. 2014a.

FIGUEIREDO, P. S.; LOIOLA, E. The Nature and Role of Complexity in Simulation Performance: The Case of Multi-Stage New Product Screening. International Journal of System Dynamics Applications, v. 3, n. 1, p. 21-46. 2014 b.

FIGUEIREDO, P. S.; LOIOLA, E.; TRAVASSOS, X. L. The Effect Of Longer Development Times On Product Pipeline Management Performance. RAC - Revista de Administração Contemporânea. v. 19, n. 4, pp. 461-485. 2015.

FIGUEIREDO, P.; JOGLEKAR, N. Dynamics of Project Screening in a Product Development Pipeline. In: 25th International Conference of The System Dynamics Society, Boston. 2007.

FORRESTER, J. W. Industrial Dynamics. MIT Press. 1961.

FORRESTER, J. W.; SENGE, P. M. Tests for building confidence in system dynamics models. TIME Studies in the Management Science, v. 14, p. 209-228. 1980.

GALAMBOS, J. The asymptotic theory of Extreme Order Statistics. John Wyley and Sons. 1978.

GINO, F.; PISANO, G. Do Managers' Heuristics Affect R\&D Performance Volatility? A Simulation Informed by the Pharmaceutical Industry. Harvard Business School Working Paper. 2005.

GIROTRA, K.; TERWISCH, C.; ULRICH, K. T. Managing the Risk of Development Failures: A Study of Late-Stage failures in the Pharmaceutical Industry. The Wharton School, University of Pennsylvania, 2005.

GRIFFIN, A. PDMA research on new product development practices: Updating trends and benchmarking best practices. Journal of Product Innovation Management, v. 14, n. 6, p. 429458. 1997. 
GUMBEL, E. J. Statistics of Extremes. Columbia University Press, New York. 1958.

HESKETT, J. L.; SASSER, W. E.; SCHLESINGER, L. A. The Service Profit Chain. New York: Free Press. 1997.

JUGEND, D.; SILVA, S. L. Integration in New Product Development: Case Study in a Large Brazilian High-Technology Company. J. Technol. Manag Innov, v. 7, n. 1, 2012.

KRISHNAN, V; ULRICH, K. Product development decisions: a review of the literature. Management Science, v. 47, p. 1-21. 2001.

LEE, H. L.; PADMANABHAN, V.; WHANG, SEUNGJIN. The Bullwhip Effect in Supply Chains. Sloan Management Review, v. 38, n. 3, p. 93-102, 1997.

LOIOLA, E.; MASCARENHAS, T. Gestão de Ativos de Propriedade Intelectual: um Estudo sobre as Práticas da Braskem S.A. Revista de Administração Contemporânea, v. 17, n. 1, p. 42-63, 2013.

OLIVA, R.; STERMAN, J. D. Cutting corners and working overtime: Quality erosion in the service industry. Management Science, v. 47, n. 7, p. 894-914, 2001.

REYCK, B.; DEGRAEVE, Z.; CRAMA, P. Project Portfolio Management at Novartis Pharma. London Business School case. 2004.

SCHMIDT, J. B.; SARANGEE, K.; MONTOYA-WEISS, M. M. Exploring New Product Development Project Review Practices and Performance. Journal of Product Innovation Management, v. 26, n. 5, p. 520-535, 2009.

SCHMIDT, J. B.; CALANTONE, R. J. Escalation of commitment during new product development. Journal of the Academy of Marketing Science, v. 30, n. 2, p. 103-118, 2002.

STERMAN, J. D. Modeling managerial behavior - Misperceptions of feedback in a dynamic decision-making experiment. Management Science, v. 35, n. 3, p. 321-339, 1989.

STERMAN, J. Business Dynamics: Systems Thinking and Modeling for a Complex World. New York: Irwin/McGraw-Hill. 2000.

SUBRAMANIAN, D.; PEKNY, J. F.; REKLAITIS, G. V.; BLAU, G. E. Simulation-optimization framework for stochastic optimization of R\&D pipeline management. AIChE Journal, v. 49, n. 1, 2003.

TERWIESCH, C.; ULRICH, K. T. Innovation Tournaments: Creating and Selecting Exceptional Opportunities, Harvard Business School Press. 2009.

THOMKE, S.; FUJIMOTO, T. The effect of "front-loading" problem-solving on product development performance. Journal of Product Innovation Management, v. 17, n. 2, p. 128-142. 2000 . 
ULRICH, K. T.; EPPINGER, S. D. Product Design and Development. Third Edition, McGraw-Hill, New York. 2004.

WHEELWRIGHT, S. C.; CLARK, K. B. Revolutionizing Product Development: Quantum Leaps in Speed, Efficiency and quality. The Free Press. 1992.

VARMA, V.A.; PEKNY, J. F.; REKLAITIS, G. V.; SUBRAMANIAN, D. An XML-based language for the Research \& Development pipeline management problem. Computers and Chemical Engineering, v. 27, n. 10, 2003.

ZAPATA, A. R. P.; CANTÚ, S. O. Gestion Estrategica De La Tecnologia En El Predesarrollo De Nuevos Productos. J. Technol. Manag. Innov, v.3,n.3, 2008.

\section{A. APPENDIX}

\section{A.1. Model Parameters}

Table A.1 - Default Parameters for Base case.

\begin{tabular}{cc}
\hline Time to adjust capacity & 8 month \\
\hline Nominal development time & 2 months \\
\hline Nominal Capacity & 5 projects/month \\
\hline Time to review a project (Review Time) & 0.1 month \\
\hline Number of Starts (I) & 5 projects/month \\
\hline Threshold1 & $1.68 \mathrm{M} \$$ \\
\hline Threshold2 & $3.09 \mathrm{M \$}$ \\
\hline a1 & 0.5 \\
\hline a2 & 0.5
\end{tabular}


